\title{
26 Research Square \\ Inhibition of Enterovirus 71 by Picochlorum sp. 122 via AKT and ATM/ATR Signaling Pathways
}

\section{Min Guo}

Guangzhou Medical University

\section{Ruilin Zheng}

Guangzhou Medical University

Hua-lian Wu

South China Sea Institute of Oceanology Chinese Academy of Sciences

\section{Danyang Chen}

Guangzhou Medical University

\section{Jingyao Su}

Guangzhou Medical University

\section{Tiantian Xu}

Guangzhou Medical University

Houbo Wu

South China Sea Institute of Oceanology Chinese Academy of Sciences

\section{Wenzhou Xiang}

South China Sea Institute of Oceanology Chinese Academy of Sciences

\section{Yinghua Li}

Guangzhou Medical University

Bing Zhu ( $\square$ zhubing@gzhmu.edu.cn )

Guangzhou Medical University https://orcid.org/0000-0001-7695-6082

\section{Research Article}

Keywords: Enterovirus 71, Picochlorum sp. 122, Signaling pathway, Apoptosis

Posted Date: June 29th, 2021

DOl: https://doi.org/10.21203/rs.3.rs-651529/v1

License: (9) This work is licensed under a Creative Commons Attribution 4.0 International License. Read Full License 


\section{Abstract}

Enterovirus 71 (EV71) pose a critical threat in global public health and may lead to severe and even lethal cases of hand-foot-and-mouth disease (HFMD). No effective antiviral agents are available to the masses for treatment of HFMD caused by EV71. Polysaccharide provides a good clinical application for antivirus. Polysaccharides extracted from Picochlorum sp. 122 (PPE) is a kind of seaweed Polysaccharides, the reports on its antiviral activity are limited. In this study, the antiviral activity was verified in Vero cells. Briefly, PPE has been demonstrated to restrain EV71 infection through MTT assay and cellular cytopathic effect. In addition, the decrease of the nucleic acid and protein levels of VP1 indicated PPE effectively inhibited the proliferation of EV71 in Vero cells. Furthermore, the annexinV-affinity assay suggested that PPE protected host cells from apoptosis. The mechanistic investigations revealed that PPE restrained EV71-induced host-cells apoptosis by AKT and ATM/ATR signaling pathways. In conclusion, these results demonstrate PPE is a hopeful antiviral drug for the infection of EV71.

\section{Introduction}

As one of the most common disease in children who are under 5 years old, hand-foot-and-mouth disease (HFMD) has become a global public health problem worldwide.[1] HFMD is principally caused by varieties of enteroviruses, such as Coxsackievirus A (CVA) and B, Echovirus 4, 6 and 7, especially enterovirus 71(EV71) and coxsackie virus A16 (Cox A16).[2] Generally, the HFMD is a self-limited disease, with the characterize of fever, oral ulcers, and skin rash on hands, feet, buttocks.[3] Unlike coxsackieviruses, EV71 infection is more occasionally to lead to severe complications, including cardiopulmonary failure, pulmonary haemorrhage, cephalitis, acute aseptic meningitis, acute flaccid paralysis, myocarditis and even to death. $[2,4]$ EV71 makes HFMD an important health concern.

EV71 is a non-enveloped, single-strand positive-sense RNA virus that belongs to the family of picornaviridae.[5] It was firstly isolated from sputum specimens of a California infant suffering from nervous system disease in 1969.[6] After that, it has been frequently reported all over the world, especially in Asia-Pacific region,[7-10] such as China,[11] Malaysia,[12] Japan,[13] Singapore,[14] Vietnam[15] and Cambodia.[16] Although there were large outbreaks occurring frequently and increased fatal HFMD associated with EV71, no effective antiviral agents are available to the masses so far.

Over the past forty years, algal products have been attracted more attention in industrial applications with the ability to produce many important compounds, such as polysaccharides(algae-based polymers), pigments, lipids and so on.[17] Algal was used in the production of food supplements and as an ingredient in aquaculture, animal feed, and an important component of soil biofertilizer.[18] Owing to its rich source, high security, low side effects and good biological activity, seaweed polysaccharide have been already proved to possess several important properties for clinical application, including tissue engineering, drug delivery, wound dressings, anticancer activity, anticoagulant activity, anti-inflammatory activity, antibacterial effect and immunomodulators.[19-21] Some studies have shown that Polysaccharides have the ability to inhibit virus replication. Polysaccharides mainly interfere with the 
attachment of the viruses to the host cell membrane, thus preventing their entrance into the host cells.[22] Picochlorum sp. PPE was isolated from the India ocean surface seawater. Polysaccharides extracted from Picochlorum sp. PPE (PPE) is a kind of seaweed Polysaccharides, but the reports on its antiviral activity are limited.

Recently, more researches have been focused on the apoptosis mechanism of EV71 inducing host cells. $\mathrm{Li}$ et al reported that EV71 induces Vero cell apoptosis by producing ROS and acting SIRT1.[23] Lei et al. found that EV71 induced neural cell apoptosis and autophagy by downregulating ACOX1 and generating ROS.[24] EV71 induced SH-SY5Y human neuroblastoma cells apoptosis by stimulating expression of endogenous microRNA let-7b reported by Du et al.[25] In this study, for the first time, the antiviral activity of PPE against EV71 was tested and the apoptosis mechanism by ROS-mediated signaling pathways was explored.

\section{Materials And Methods \\ 2.1 Materials}

PPE was obtained from Xi'an Sanjiang Biological Engineering Co. Ltd. 3-[4,5-dimethylthiazol-2-yl]-2,5diphenyl tetrazolium bromide (MTT), 4',6-Diamidino-2-phenyindole (DAPI), propidium iodide (PI), AnnexinV-FLUOS staining kit were acquired from ChinaPeptides Co. Ltd. Both antibodies and BCA protein assay kit that used for western blot analysis were purchased from Cell signaling Technology (CST).

\subsection{Cell and virus culture}

Vero cells were obtained from ATCC (Manassas, VA, USA) and were cultured in complete Dulbecco's Modifed Eagle's Medium (DMEM) supplemented with $10 \%$ fetal bovine serum and $1 \%$ antibiotic (penicillin/streptomycin) at $37^{\circ} \mathrm{C}$ in a humidified incubator with $5 \% \mathrm{CO}_{2}$. The prototype EV71 was provided by the Virus Laboratory, Guangzhou Women and Children's Medical Center, Guangzhou Medical University.

EV71 infection was performed and 50\% tissue culture infective dose (TCID50) was calculated by the method of Reed and Muench as previously described. [26] Briefly, Vero cells were grown to $75 \%$ confluence and then infected with EV71 for $2 \mathrm{~h}$ for virus absorption. After infection, the cells were washed with PBS and then maintained at $37^{\circ} \mathrm{C}$ in serum-free medium.

\subsection{Cell viability assay}

The cytotoxicity of PPE on Vero cells was measured by a method by MTT assay as described earlier. In brief, Vero cells were inoculated into 96 -well plates in the amount of $5 \times 10^{4} /$ well and then cultured at $37^{\circ} \mathrm{C}$ for 24 hours. The final titer of EV71 used in this study was 100 TCID $_{50}$. After treatment with EV71 for $24 \mathrm{~h}$, the cells were rinsed twice with PBS and $15 \mu \mathrm{L}$ MTT $(5 \mathrm{mg} / \mathrm{mL})$ solutions were added into each well. After $4 \mathrm{~h}, 150 \mu \mathrm{L} /$ well of Dimethyl sulfoxide (DMSO) was added to dissolve formazan crystal formed by live 
cell. The absorbance at $570 \mathrm{~nm}$ was detected by a microplate spectrophotometer. The $\mathrm{IC}_{50}$ values of Vero cell treatment with different concentration of PPE were calculated.

\subsection{VP1 gene detection by qRT-PCR quantification}

To verify the inhibitory effect of PPE on EV71 virus in Vero cell, the gene expression level of VP1 was quantitatively detected by a real-time qRT-PCR assay. According to our previous report,[27] the primers used in the Q-PCR experiment were shown below: VP1 (forward primer, 5'GATATCCCACATTCGGTGA 3', reverse primer 5'TAGGACACGCTCCATACTCAAG 3') and ß-actin primers (forward 5'TGACGGGGTCACCCACACTGTGCCCATCTA3', reverse5'CTAGAAGCATTTGCGGTGGACGATG 3'). The comparative cycle threshold (Ct) calculation was calculated by $2^{-\triangle \triangle C t}$ method to measure the relative gene expression levels of VP1 mRNA.

\subsection{Annexin-V/PI double-staining assay}

The Vero cells were treated and collected as described earlier.[28] Briefly, the harvested cells were suspended with PBS and centrifuged at $1000 \mathrm{rpm}$ for $5 \mathrm{~min}$. The supernatant were discarded and the cells were suspended with $195 \mu \mathrm{L}$ binding buffer. Finally, the cells were stained with $5 \mu$ I Annexin V-FITC and $10 \mu \mathrm{II}$ at room temperature for 10-20 minutes away from light. A least 10000 cells per sample were tested and dates were collected by Cell Quest $\mathrm{V}^{\mathrm{TM}}$ software.

\subsection{Western blot analysis}

The expression levels of various proteins involved in signaling pathways were determined by Western blot analysis, as previous reports. [29] The Vero cells treated with PPE after EV71 infection were lysed and the total proteins were obtained. The protein quantitation was determined using BCA assay. Then equal amounts of Proteins $(20 \mu \mathrm{g})$ were separated by sodium dodecyl sulfate (SDS)-polyacrylamide gel and transferred onto a PVDF membrane. Then the membranes were incubated with first and second antibodies separately. The antibodies used were as below: AKT, p-ATM, p-ATR, The bolts were all visualized with enhanced chemiluminescence $(E C L)$ reagent.

\subsection{Statistical analysis}

Experiments were performed and repeated at least three times. All the data are presented as mean \pm standard deviation. Oneway analysis of variance was performed for comparison among three or more groups. Values of $\star P<0.05$ or $* \star P<0.01$ were regarded as indicating a statistically significant difference.

\section{Results And Discussion}

\subsection{In vitro antiviral effect of PPE}

To evaluate the cytotoxic effects of EV71 and the protective effects of PPE, cell viability was determined with different concentrations by a MTT assay. As shown in Fig. 1A, Vero cells treated with PPE at the concentration of $62.5 \mu \mathrm{g} / \mathrm{ml}, 125 \mu \mathrm{g} / \mathrm{ml}$ and $250 \mu \mathrm{g} / \mathrm{ml}$ after EV71 infection showed a cell viability of 
$79.5 \%, 85.1 \%$ and $92 \%$, respectively. PPE revealed a trend to dose-dependently protect of the Vero cells on cell proliferation. As depicted in Fig. 1B, Vero cells treated with EV71 virus showed the cytopathic effects (CPE), cytoplasmic shrinkage, decline in cells numbers and loss of cell-to-cell contact. However, the CPE were attenuated by dealing with PPE. In brief, PPE effectively protected Vero cells from EV71 infection.

\subsection{EV71 virus proliferation was inhibited by PPE}

The viral RNA encodes four capsid proteins including VP1, VP2, VP3 and VP4. [5, 30] Among them, VP1 is the most external and immunogenic structural protein.[5, 31] To quantify the proliferation of EV71 virus, amplification of VP1 was performed by Q-PCR assay. As shown in Fig. 2A, compare to EV71 virus group, the level of VP1 mRNA expression was reduced to $1.2 \%, 35 \%, 40 \%$ in the treatment of PPE at the concentration of $250 \mu \mathrm{g} / \mathrm{ml}, 125 \mu \mathrm{g} / \mathrm{ml}, 62.5 \mu \mathrm{g} / \mathrm{ml}$. Similarly, as show in Fig. 2B, the level of VP1 protein expression was remarkably decreased by treatment with PPE. These results all directly suggested that PPE showed high efficacy to suppress the proliferation of EV71 virus.

\subsection{PPE protected host cells from apoptosis}

The host cell may alter some specific biological pathways after virus infections, such as apoptosis, differentiation, and so on.[32] On basis of a double-labeling for annexin $\mathrm{V}$ and PI, vital, dead and apoptotic cells can be discriminated. After $24 \mathrm{~h}$ of induction, cells with the characteristic morphological features of apoptosis became visible. To quantitate the apoptotic cells percentages of Vero cells after EV71 infection, a method of flow cytometry was performed. As shown in Fig. 3, the percentage of the apoptotic cell was dramatically elevated from $11.43 \%$ (uninfected control group) to $36.54 \%$ (EV71 infected group). After treatment with different concentrations of PPE, the apoptotic cell population of Vero cells were obviously decreased to $33.56 \%, 29.64 \%$ and $23.99 \%$, respectively, indicating that the PPE showed the antivirus ability in EV71-infected Vero cell in a dose-dependent manner. The result directly revealed that PPE exhibited strong antivirus ability to prevent Vero cells from apoptosis.

\subsection{Activation of AKT and ATM/ATR signaling pathways by PPE}

Many reports showed that EV71 could induce host cells apoptosis. Vero cells infected with EV71 virus were treated with different concentrations of PPE for 48 hours. Proteins related to apoptosis signaling pathways were detected by Western blot analysis. ATM Kinase involved in mediating various biological responses including apoptosis, cell cycle checkpoints factors and DNA repair. As shown in Fig. 4, EV71 virus infection caused an increased expression of ATM and ATR. However, the proteins expression level of ATM and ATR were significantly downregulated in PPE treatment group. AKT Kinase is a Serine/threonine Kinase which is involved in inhibition of Apoptosis and stimulation of cell proliferation. As shown in Fig. 4 the protein expression level of AKT evidently decreased in cells infected by EV71 virus without subsequent treatments, but obviously increased after treatment with PPE. Taken together, the results indicate that PPE restrained EV71-induced host-cells apoptosis by AKT and ATM/ATR signaling pathways (Fig. 5). 


\section{Conclusions}

EV71 associated with HFMD has been a threat to the health of children worldwide. In this study, the antivirus activity and mechanisms of PPE (a kind of seaweed Polysaccharides) was evaluated. Our study demonstrated PPE efficiently restrain EV71 proliferation and protected Vero cells from apoptosis. The underlying mechanisms suggested that PPE restrained EV71-induced host-cells apoptosis by AKT and ATM/ATR signaling pathways. Our findings revealed that PPE might become a potential candidate drug for treatment of EV71 infection.

\section{Declarations}

\section{Conflicts of interest}

The authors report no conflicts of interest in this work.

\section{Data Availability Statement}

Data sharing not applicable to this article as no datasets were generated or analysed during the current study.

\section{Acknowledgements}

This work was supported by the Pediatrics Institute Foundation of Guangzhou Women and Children's Medical Centre (YIP-2019-059), the Guangdong Natural Science Foundation (2020A1515110648), the Open Fund of Guangdong Provincial Key Laboratory of Functional Supramolecular Coordination Materials and Applications (2020A03), Open Project of Guangdong Key Laboratory of Marine Materia Medica (LMM2020-7). Technology Planning Project of Guangzhou (202102010202). The Guangzhou Medical University Students' Science and Technology Innovation Project (2019AEK02, 2020AEK03, 2020AEK06 and 2020AEK12).

\section{References}

1. Z. Xu, W. Hu, K. Jiao, C. Ren, B. Jiang and W. Ma, BMC Infect Dis, 2019, 19, 969-969.

2. G. Gonzalez, M. J. Carr, M. Kobayashi, N. Hanaoka and T. Fujimoto, Int J Mol Sci, 2019, 20, 1-6.

3. Y. Wang, H. Zhao, R. Ou, H. Zhu, L. Gan, Z. Zeng, R. Yuan, H. Yu and M. Ye, BMC Public Health, 2020, 20, 801-801.

4. L. Chen, S.-J. Xu, X.-J. Yao, H. Yang, H.-L. Zhang, J. Meng, H.-R. Zeng, X.-H. Huang, R.-L. Zhang and Y.Q. He, Arch Virol, 2020, 165, 2213-2227.

5. S. Phanthong, J. Densumite, W. Seesuay, J. Thanongsaksrikul, S. Teimoori, N. Sookrung, Y. Poovorawan, N. Onvimala, R. Guntapong, K. Pattanapanyasat and W. Chaicumpa, Front Microbiol, 2020, 11, 562768-562768.

6. N. J. Schmidt, E. H. Lennette and H. H. Ho, The Journal of infectious diseases, 1974, 129, 304-309. 
7. H. Sun, M. Gao and D. Cui, Gut Pathog, 2020, 12, 1-11.

8. T. Solomon, P. Lewthwaite, D. Perera, M. J. Cardosa, P. McMinn and M. H. Ooi, The Lancet. Infectious diseases, 2010, 10, 778-790.

9. M. G. Wang, H. M. Sun, X. M. Liu and X. Q. Deng, European review for medical and pharmacological sciences, 2017, 21, 43-49.

10. Z. Yang, F. Gao, X. Wang, L. Shi, Z. Zhou, Y. Jiang, X. Ma, C. Zhang, C. Zhou, X. Zeng, G. Liu, J. Fan, Q. Mao and L. Shi, Human vaccines \& immunotherapeutics, 2020, 16, 1602-1610.

11. T.-C. Chan, J.-S. Hwang, R.-H. Chen, C.-C. King and P.-H. Chiang, BMC Public Health, 2014, 14, 11-11.

12. L. C. Lum, K. T. Wong, S. K. Lam, K. B. Chua, A. Y. Goh, W. L. Lim, B. B. Ong, G. Paul, S. AbuBakar and M. Lambert, The Journal of pediatrics, 1998, 133, 795-798.

13. M. Takechi, W. Fukushima, T. Nakano, M. Inui, S. Ohfuji, T. Kase, K. Ito, K. Kondo, A. Maeda, H. Shimizu and Y. Hirota, Journal of epidemiology, 2019, 29, 354-362.

14. S. Singh, V. T. K. Chow, M. C. Phoon, K. P. Chan and C. L. Poh, J Clin Microbiol, 2002, 40, 2823-2827.

15. N. T. B. Nguyen, H. V. Pham, C. Q. Hoang, T. M. Nguyen, L. T. Nguyen, H. C. Phan, L. T. Phan, L. N. Vu and N. N. Tran Minh, BMC Infect Dis, 2014, 14, 341-341.

16. P. F. Horwood, A. Andronico, A. Tarantola, H. Salje, V. Duong, C. Mey, S. Ly, P. Dussart, S. Cauchemez and P. Buchy, Emerg Infect Dis, 2016, 22, 92-95.

17. R. H. Wijffels and M. J. Barbosa, Science, 2010, 329, 796-799.

18. J. Lian, R. H. Wijffels, H. Smidt and D. Sipkema, Microbial biotechnology, 2018, 11, 806-818.

19. M. F. de Jesus Raposo, A. M. de Morais and R. M. de Morais, Marine drugs, 2015, 13, 2967-3028.

20. F. Kholiya, S. Chatterjee, G. Bhojani, S. Sen, M. Barkume, N. K. Kasinathan, J. Kode and R. Meena, Carbohydrate polymers, 2020, 240, 1-11.

21. T. Okimura, Z. Jiang, H. Komatsubara, K. Hirasaka and T. Oda, International journal of biological macromolecules, 2020, 154, 1116-1122.

22. E. Abu-Galiyun, M. Huleihel and O. Levy-Ontman, Cell cycle (Georgetown, Tex.), 2019, 18, 3540-3549.

23. H. Li, Z. Bai, C. Li, C. Sheng and X. Zhao, Journal of cellular biochemistry, 2020, 121, 4321-4331.

24. L. You, J. Chen, W. Liu, Q. Xiang, Z. Luo, W. Wang, W. Xu, K. Wu, Q. Zhang, Y. Liu and J. Wu, Virulence, 2020, 11, 537-553.

25. X. Du, H. Wang, F. Xu, Y. Huang, Z. Liu and T. Liu, Molecular medicine reports, 2015, 12, 953-959.

26. S. D. Molloy, M. R. Pietrak, I. Bricknell and D. A. Bouchard, Applied and environmental microbiology, 2013, 79, 5882-5890.

27. J. Zhong, Y. Xia, L. Hua, X. Liu, M. Xiao, T. Xu, B. Zhu and H. Cao, Artif Cells Nanomed Biotechnol, 2019, 47, 3485-3491.

28. M. Guo, Y. Li, Z. Lin, M. Zhao, M. Xiao, C. Wang, T. Xu, Y. Xia and B. Zhu, RSC Advances, 2017, 7, 52456-52464. 
29. Y. Li, M. Guo, Z. Lin, M. Zhao, M. Xiao, C. Wang, T. Xu, T. Chen and B. Zhu, Int J Nanomedicine, 2016, 11, 6693-6702.

30. P. Plevka, R. Perera, J. Cardosa, R. J. Kuhn and M. G. Rossmann, Science, 2012, 336, 1274-1274.

31. T. Meng, Q. Jia, S.-M. Wong and K.-B. Chua, J Virol, 2019, 93, e00061-00019.

32. R. Y. L. Wang, K. F. Weng, Y. C. Huang and C. J. Chen, Scientific reports, 2016, 6, 1-10.

\section{Figures}

A
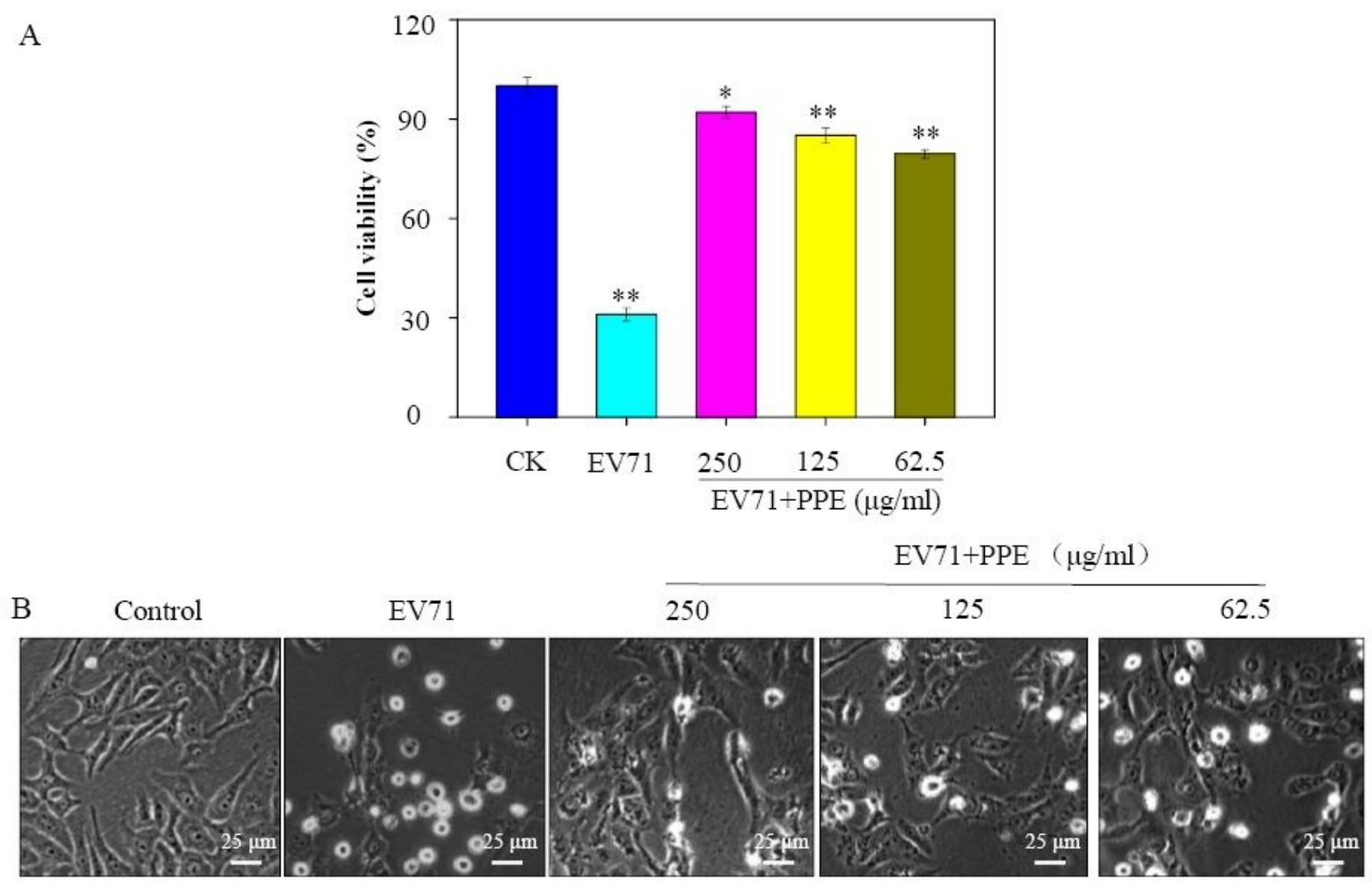

\section{Figure 1}

Effects of PPE on the growth of Vero cells infected EV71 by MTT assay. (A) Antiviral activity of PPE was measured by MTT assay. The concentrations of PPE was $250 \mu \mathrm{g} / \mathrm{ml}, 125 \mu \mathrm{g} / \mathrm{ml}$ and $62.5 \mu \mathrm{g} / \mathrm{ml}$ respectively. (B) Morphological changes in EV71 infected Vero cells observed by phase-contrast microscopy. 
A

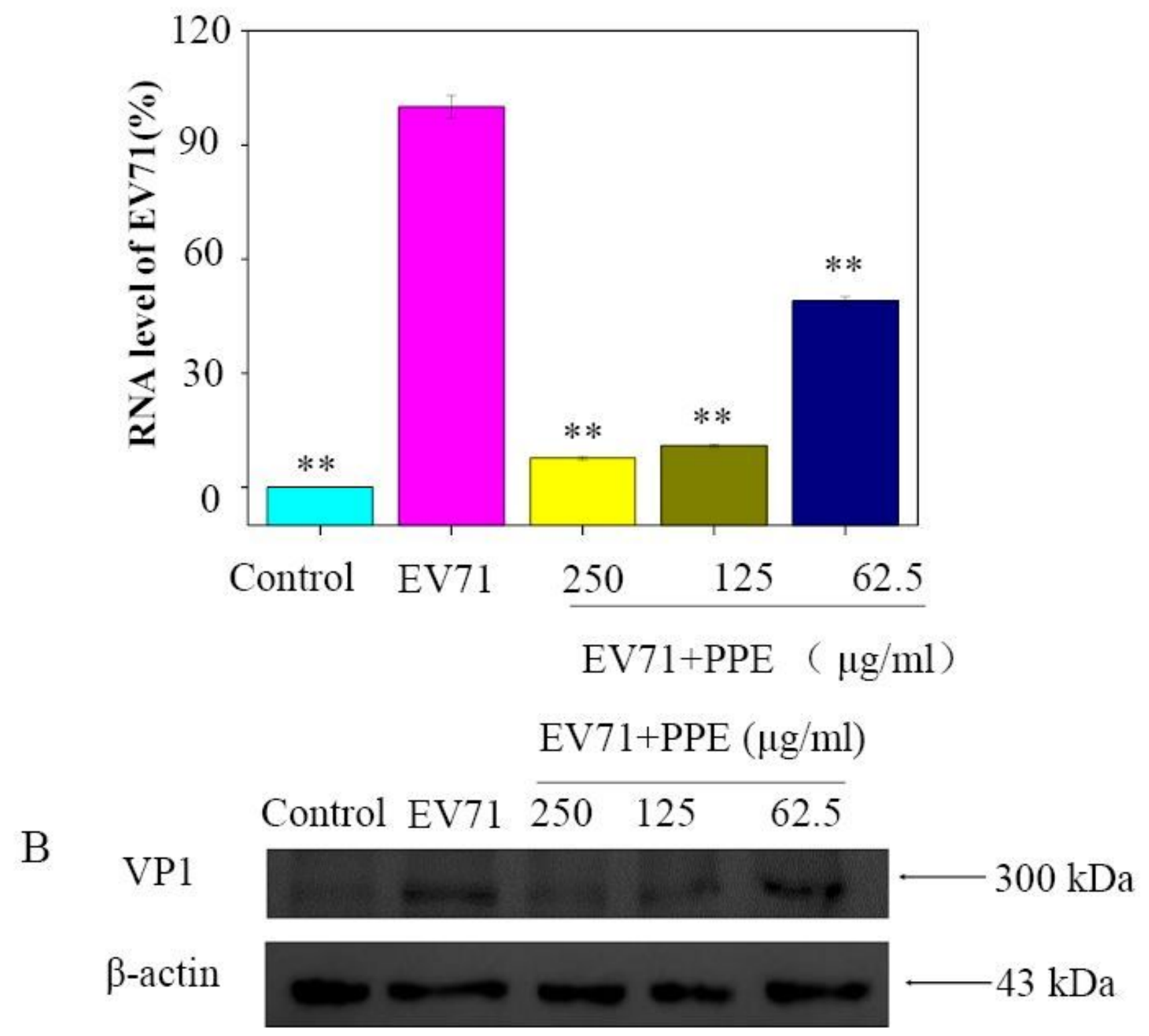

Figure 2

The proliferation of EV71 virus was effectively suppressed by PPE. (A) The gene expression levels of VP1 mRNA was measured by a real-time qRT-PCR assay. (B) The protein expression levels of VP1 was detected by Western blotting. $\beta$-Actin was used as the loading control. The concentrations of PPE was $250 \mu \mathrm{g} / \mathrm{ml}, 125 \mu \mathrm{g} / \mathrm{ml}$ and $62.5 \mu \mathrm{g} / \mathrm{ml}$ respectively. 


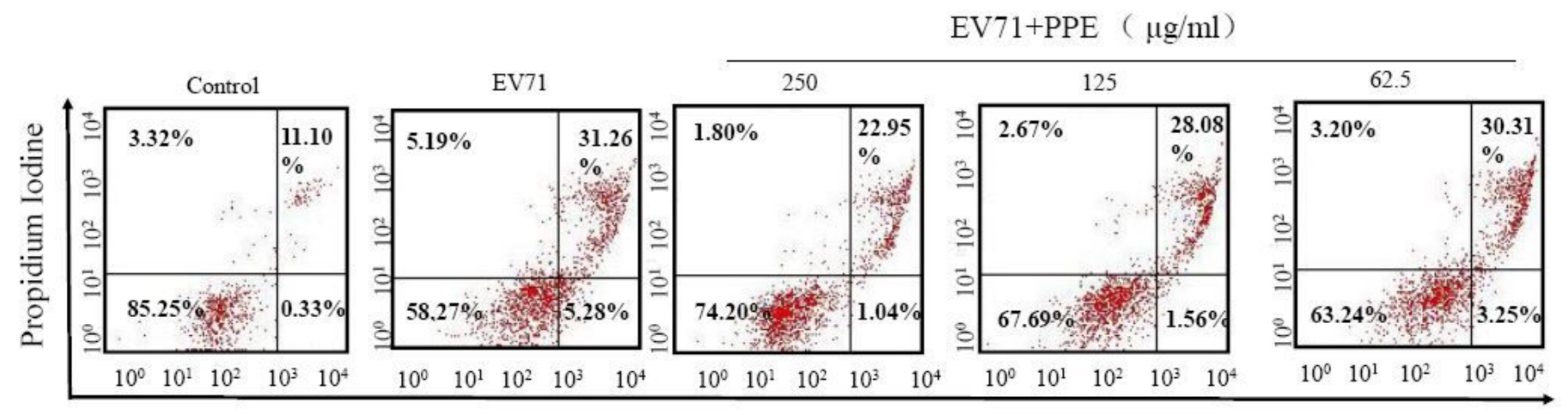

Annexin V-FITC

\section{Figure 3}

Translocation of phosphatidylserine induced by EV71 in vero cells. The concentrations of PPE was 250 $\mu \mathrm{g} / \mathrm{ml}, 125 \mu \mathrm{g} / \mathrm{ml}$ and $62.5 \mu \mathrm{g} / \mathrm{ml}$ respectively. The upper right quadrant represented cells in the early apoptosis.

\section{EV71 +PPE}

Control Virus $250 \quad 125 \quad 62.5(\mu \mathrm{g} / \mathrm{ml})$

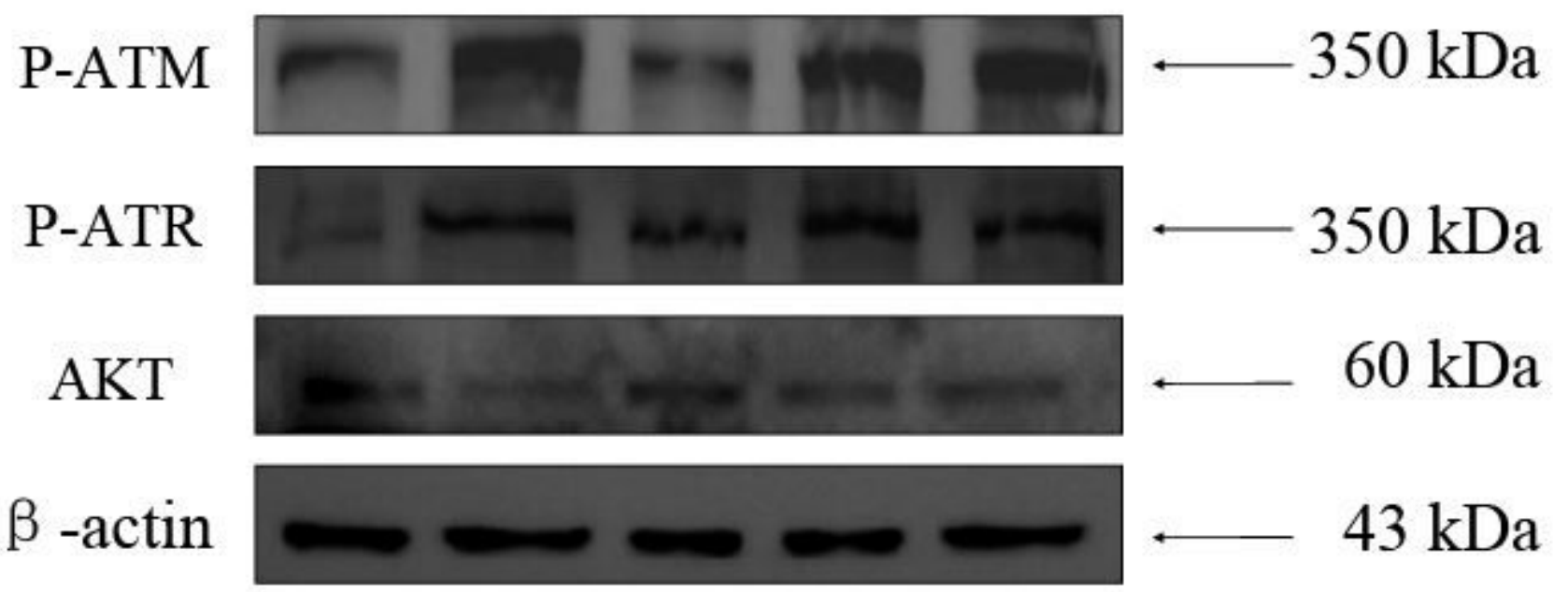

Figure 4

Intracellular apoptotic signaling pathways triggered by EV71 in vero cells. Phosphorylation status expression levels of p-ATM, p-ATR pathways and activation of AKT signaling pathway. $\beta$-Actin was used as the loading control. 


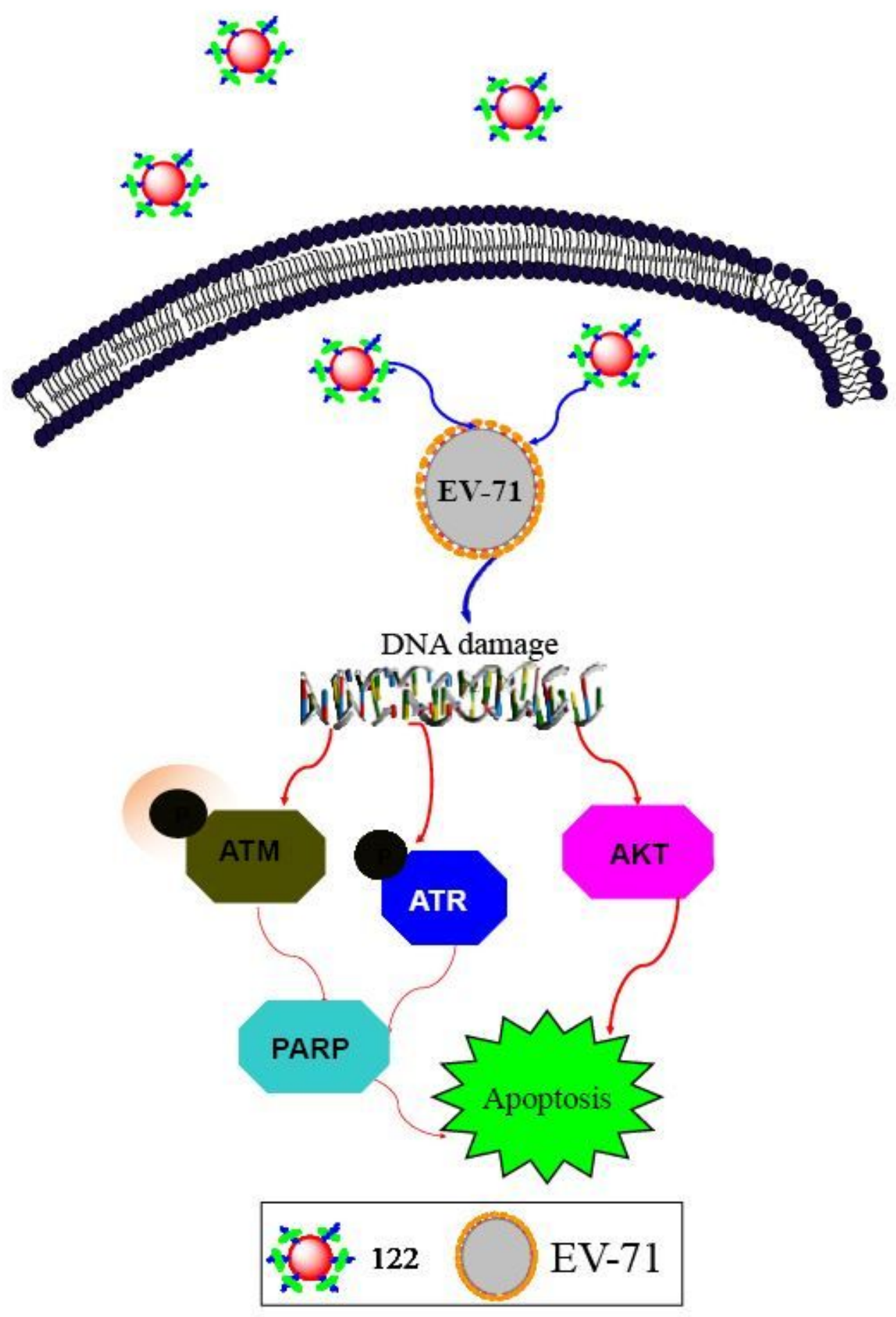

Figure 5

The overview of the apoptosis signaling pathway caused by EV71 in vero cells was described by a sketch. 